\title{
Perceived Discrimination, Trust in Physicians, and Prolonged Symptom Duration Before Ovarian Cancer Diagnosis in the African American Cancer Epidemiology Study
}

\author{
Megan A. Mullins, MPH (D) 1; Lauren C. Peres, $\mathrm{PhD}^{2}$; Anthony J. Alberg, PhD ${ }^{3}$; Elisa V. Bandera, MD, PhD ${ }^{4}$; \\ Jill S. Barnholtz-Sloan, PhD (iD 5; Melissa L. Bondy, PhD ${ }^{6}$; Ellen Funkhouser, PhD ${ }^{7}$; Patricia G. Moorman, PhD ${ }^{8}$; \\ Edward S. Peters, DMD, ScD (iD 9; Paul D. Terry, PhD (iD 10; Ann G. Schwartz, PhD ${ }^{11}$; Andrew B. Lawson, PhD ${ }^{12}$; \\ Joellen M. Schildkraut, PhD $^{13}$; and Michele L. Cote, $P h D^{11}$
}

\begin{abstract}
BACKGROUND: Discrimination and trust are known barriers to accessing health care. Despite well-documented racial disparities in the ovarian cancer care continuum, the role of these barriers has not been examined. This study evaluated the association of everyday discrimination and trust in physicians with a prolonged interval between symptom onset and ovarian cancer diagnosis (hereafter referred to as prolonged symptom duration). METHODS: Subjects included cases enrolled in the African American Cancer Epidemiology Study, a multisite case-control study of epithelial ovarian cancer among black women. Logistic regression was used to calculate odds ratios (ORs) and 95\% confidence intervals ( $\mathrm{Cls}$ ) for associations of everyday discrimination and trust in physicians with a prolonged symptom duration (1 or more symptoms lasting longer than the median symptom-specific duration), and it controlled for access-to-care covariates and potential confounders. RESULTS: Among the 486 cases in this analysis, 302 women had prolonged symptom duration. In the fully adjusted model, a 1-unit increase in the frequency of everyday discrimination increased the odds of prolonged symptom duration $74 \%(\mathrm{OR}, 1.74 ; 95 \% \mathrm{Cl}, 1.22-2.49)$, but trust in physicians was not associated with prolonged symptom duration (OR, 0.86; 95\% Cl, 0.66-1.11). CONCLUSIONS: Perceived everyday discrimination was associated with prolonged symptom duration, whereas more commonly evaluated determinants of access to care and trust in physicians were not. These results suggest that more research on the effects of interpersonal barriers affecting ovarian cancer care is warranted. Cancer 2019;125:4442-4451. (C) 2019 American Cancer Society.
\end{abstract}

KEYWORDS: access to care, ovarian cancer, perceived discrimination, prolonged symptoms, racial disparity.

\section{INTRODUCTION}

Ovarian cancer is the most lethal gynecologic cancer, with less than $50 \%$ of women surviving 5 years or longer after their diagnosis. ${ }^{1}$ Compared with white women, black women have a lower 5 -year survival rate for all histologic subtypes of ovarian cancer at all stages of diagnosis. ${ }^{2}$ Moreover, compared with 1975 rates, 5-year survival has improved approximately $10 \%$ for white women with ovarian cancer but has declined for black women. ${ }^{3}$

\begin{abstract}
Corresponding author: Megan A. Mullins, MPH, Department of Epidemiology, School of Public Health, University of Michigan, 1415 Washington Heights, Ann Arbor, MI 48109; mamull@umich.edu

${ }^{1}$ Department of Epidemiology, School of Public Health, University of Michigan, Ann Arbor, Michigan; ${ }^{2}$ Department of Cancer Epidemiology, H. Lee Moffitt Cancer Center and Research Institute, Tampa, Florida; ${ }^{3}$ Department of Epidemiology and Biostatistics, Arnold School of Public Health, University of South Carolina, Columbia, South Carolina; ${ }^{4}$ Cancer Prevention and Control Program, Rutgers Cancer Institute of New Jersey, New Brunswick, New Jersey; ${ }^{5}$ Case Comprehensive Cancer Center, Case Western Reserve University School of Medicine, Cleveland, Ohio; ${ }^{6}$ Cancer Prevention and Population Sciences Program, Baylor College of Medicine, Houston, Texas; ${ }^{7}$ Division of Preventive Medicine, University of Alabama at Birmingham, Birmingham, Alabama; ${ }^{8}$ Cancer Control and Population Sciences, Department of Community and Family Medicine, Duke University School of Medicine, Durham, North Carolina; ${ }^{9}$ Epidemiology Program, Louisiana State University Health Sciences Center School of Public Health, New Orleans, Louisiana; ${ }^{10}$ Department of Medicine, Graduate School of Medicine, University of Tennessee, Knoxville, Tennessee; ${ }^{11}$ Population Studies and Disparities Research Program, Department of Oncology, Wayne State University School of Medicine and Karmanos Cancer Institute, Detroit, Michigan; ${ }^{12}$ Hollings Cancer Center and Department of Public Health Sciences, Medical University of South Carolina, Charleston, South Carolina; ${ }^{13}$ Department of Public Health Sciences, University of Virginia, Charlottesville, Virginia
\end{abstract}

We thank Dr. Jennifer Griggs for her expertise and assistance with this article. We acknowledge the African American Cancer Epidemiology Study interviewers: Christine Bard, LaTonda Briggs, and Whitney Franz (North Carolina) and Robin Gold (Detroit, Michigan). We also acknowledge those responsible for facilitating case ascertainment at the 11 geographic locations across the 10 study centers: Jennifer Burczyk-Brown (Alabama); Rana Bayakly and Vicki Bennett (Georgia); the Louisiana Tumor Registry; Manisha Narang (New Jersey); Diana Slone, Yingli Wolinsky, Steven Waggoner, Anne Heugel, Nancy Fusco, Kelly Ferguson, Peter Rose, Deb Strater, Taryn Ferber, Donna White, Lynn Borzi, Eric Jenison, Nairmeen Haller, Debbie Thomas, Vivian von Gruenigen, Michele McCarroll, Joyce Neading, John Geisler, Stephanie Smiddy, David Cohn, Michele Vaughan, Luis Vaccarello, Elayna Freese, James Pavelka, Pam Plummer, William Nahhas, Ellen Cato, John Moroney, Mark Wysong, Tonia Combs, Marci Bowling, Brandon Fletcher, and Yingli Wolinsky (Ohio); Susan Bolick, Donna Acosta, and Catherine Flanagan (South Carolina); Martin Whiteside (Tennessee); and Georgina Armstrong and the Texas Registry (Cancer Epidemiology and Surveillance Branch, Department of State Health Services).

Additional supporting information may be found in the online version of this article.

DOI: 10.1002/cncr.32451, Received: April 24, 2019; Revised: July 8, 2019; Accepted: July 11, 2019, Published online August 15, 2019 in Wiley Online Library (wileyonlinelibrary.com) 


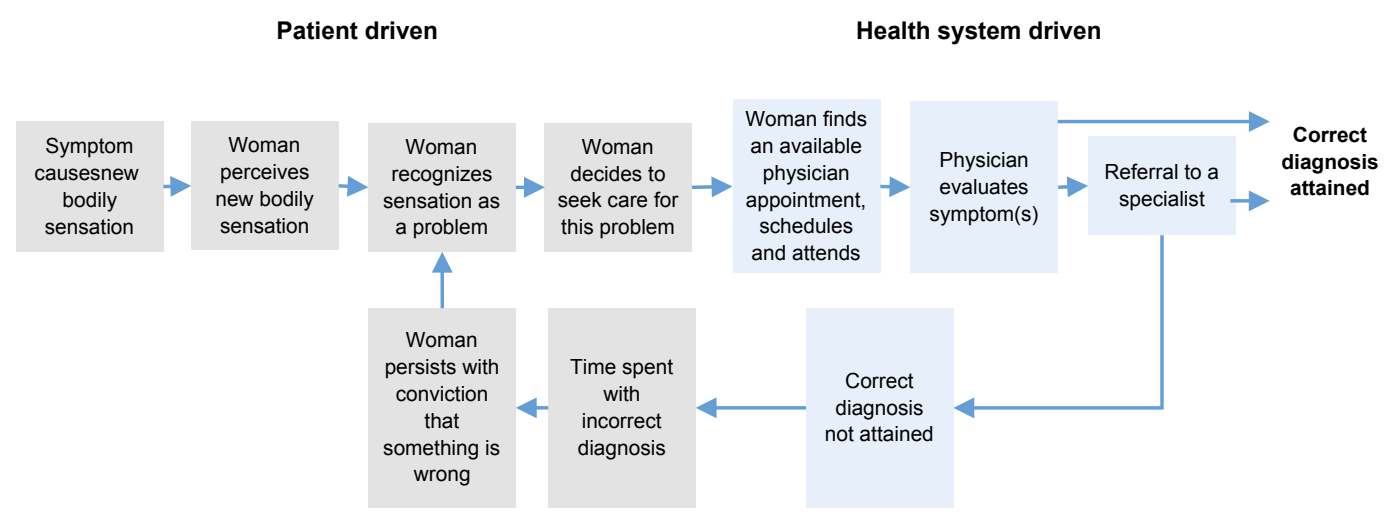

Figure 1. Patient flow before an ovarian cancer diagnosis.

Racial disparities in ovarian cancer care are well documented at all stages of the care continuum., Access to care is one key component of high-quality cancer care that may explain differences in ovarian cancer treatment. Although health insurance and socioeconomic status affect access to care, these factors alone fail to account for racial disparities in ovarian cancer treatment. ${ }^{6,7}$ Trust in physicians and perceived discrimination are 2 interpersonal factors that could contribute to these racial differences. Previously unstudied among women with ovarian cancer, these factors are associated with lower health care utilization, less preventive screening, nonadherence to care recommendations, and delays in care seeking in other patient populations. ${ }^{8-10}$

Here, we examine the association of everyday discrimination and trust in physicians with a prolonged interval between symptom onset and ovarian cancer diagnosis (hereafter referred to as prolonged symptom duration) in the African American Cancer Epidemiology Study (AACES). As depicted in Figure 1, prolonged symptom duration encompasses a series of events that must occur between a symptomatic change in the body and a woman's receipt of a diagnosis of ovarian cancer. This portion of the care continuum is particularly important for women with ovarian cancer because there is no screening or annual examination with clear guidelines on when to seek care, and ovarian cancer symptoms are nonspecific. This places more of a burden on patients to initiate and continue seeking/accessing care when symptoms do not resolve (Fig. 1). ${ }^{11,12}$ We hypothesize that low trust in physicians and more frequent perceived discrimination contribute to prolonged symptom duration.

\section{MATERIALS AND METHODS}

\section{Study Population}

The AACES has been described in detail elsewhere. ${ }^{13}$ In brief, AACES is a multisite, population-based, casecontrol study of ovarian cancer in black women. Study sites include Alabama, Georgia, Illinois, Louisiana, metropolitan Detroit, Michigan, North Carolina, New Jersey, Ohio, South Carolina, Tennessee, and Texas. Institutional review board approval was obtained from all participating sites. Cases were identified via rapid case ascertainment through state or Surveillance, Epidemiology, and End Results cancer registries and hospital gynecologic oncology departments, and they were enrolled between December 2010 and December 2015. Self-identified black women between the ages of 20 and 79 years who were newly diagnosed with histologically confirmed invasive epithelial ovarian cancer and could complete an interview in English were eligible to participate.

\section{Data Collection}

AACES participants completed a computer-assisted telephone interview. A short version was offered to women who would have otherwise refused to participate. Cases were excluded from this analysis if they had missing data (Fig. 2). Confounding variables were selected a priori on the basis of published literature. Selected confounders included the following: age at diagnosis, geographic region, marital status, body mass index, Charlson Comorbidity Index, education, and income.

\section{Independent Variables}

Perceived discrimination was evaluated with the 5question version of the Williams Everyday Discrimination 


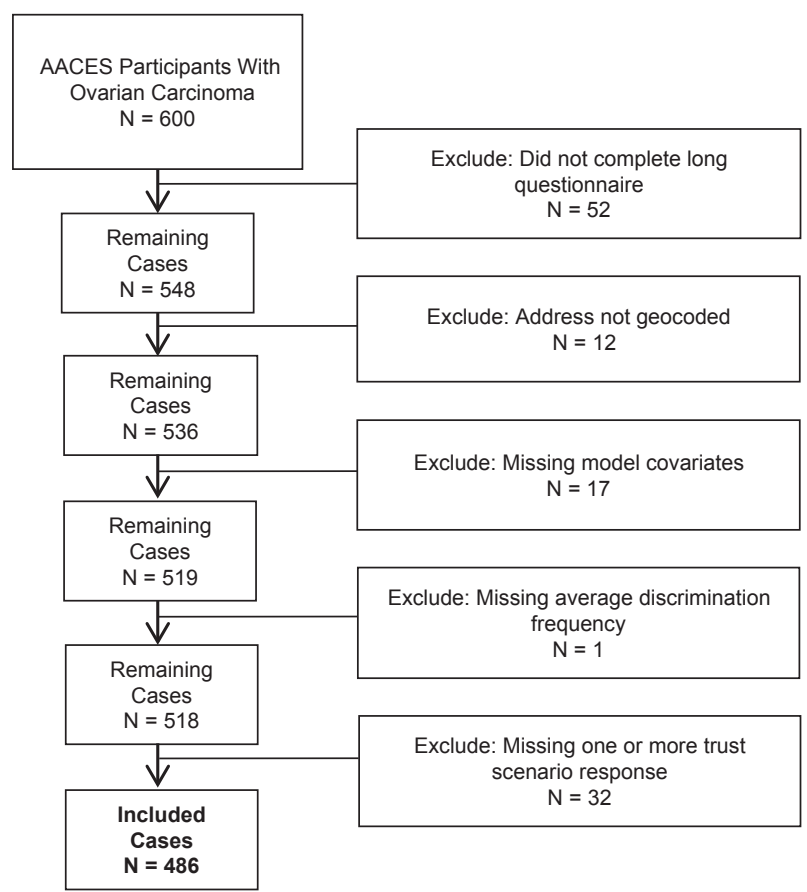

Figure 2. Patient exclusion flow diagram. AACES indicates African American Cancer Epidemiology Study.

Scale (Table 1). ${ }^{14}$ We averaged each woman's responses (range, 0-5) for the score such that a higher score reflected more frequent discrimination. Scale items were evaluated for internal consistency with Cronbach's $\alpha$.

Trust in physicians was measured with the Trust in Physician Scale (Table 2). ${ }^{15}$ Questions were coded so that a higher score indicated higher trust, and responses were summed across the 11 questions (range, 0-55). Scale items were evaluated for internal consistency with Cronbach's $\alpha$.

\section{Outcome}

The primary outcome for this study was prolonged symptom duration. Given the lack of symptom-specific durations in the literature, we defined prolonged symptom duration with respect to other women in the AACES. Women were asked whether/how long in the year before their diagnosis they had symptoms (Supporting Table 1). Because each symptom has unique meaning and urgency and most women do not have all possible symptoms, a median duration was calculated for each symptom only among women who had the symptom. Women who had any symptom longer than the median symptom-specific duration were classified as having prolonged symptom duration.
TABLE 1. Everyday Discrimination Scenario Frequencies in the AACES

\begin{tabular}{|c|c|}
\hline Discrimination Scenario & $\begin{array}{l}\text { No. of AACES } \\
\text { Participants (\%) }\end{array}$ \\
\hline \multicolumn{2}{|c|}{$\begin{array}{l}\text { You are treated with less courtesy or respect than } \\
\text { other people }\end{array}$} \\
\hline Almost everyday & $13(2.7)$ \\
\hline At least once a week & $5(1.0)$ \\
\hline A few times a month & $17(3.5)$ \\
\hline A few times a year & $38(7.8)$ \\
\hline Less than once a year & 84 (17.3) \\
\hline Never & $329(67.7)$ \\
\hline \multicolumn{2}{|c|}{$\begin{array}{l}\text { You receive poorer service than other people at } \\
\text { restaurants or stores }\end{array}$} \\
\hline Almost everyday & $0(0.0)$ \\
\hline At least once a week & $4(0.8)$ \\
\hline A few times a month & $11(2.3)$ \\
\hline A few times a year & 54 (11.2) \\
\hline Less than once a year & 89 (18.4) \\
\hline Never & $326(67.4)$ \\
\hline \multicolumn{2}{|c|}{ People act as if they think you are not smart } \\
\hline Almost everyday & $9(1.9)$ \\
\hline At least once a week & $6(1.2)$ \\
\hline A few times a month & $22(4.5)$ \\
\hline A few times a year & $46(9.5)$ \\
\hline Less than once a year & $74(15.3)$ \\
\hline Never & 327 (67.6) \\
\hline \multicolumn{2}{|c|}{ People act as if they are afraid of you } \\
\hline Almost everyday & $9(1.9)$ \\
\hline At least once a week & $4(0.8)$ \\
\hline A few times a month & $10(2.1)$ \\
\hline A few times a year & $22(4.5)$ \\
\hline Less than once a year & $22(4.5)$ \\
\hline Never & $418(86.2)$ \\
\hline \multicolumn{2}{|c|}{ You are threatened or harassed } \\
\hline Almost everyday & $1(0.2)$ \\
\hline At least once a week & $3(0.6)$ \\
\hline A few times a month & $5(1.0)$ \\
\hline A few times a year & $11(2.3)$ \\
\hline Less than once a year & $25(5.2)$ \\
\hline Never & $440(90.7)$ \\
\hline
\end{tabular}

Abbreviation: AACES, African American Cancer Epidemiology Study. Values may not sum to the total because of missing responses for some discrimination scenarios.

\section{Statistical Analyses}

Demographic characteristics were summarized with $t$ tests, Mann-Whitney $U$ tests (for everyday discrimination and income based on histogram distributions), or $\chi^{2}$ tests to compare distributions between women who had prolonged symptom duration and those who did not. Unconditional multivariable logistic regression was performed to calculate odds ratios (ORs) and 95\% confidence intervals (CI) for the associations of trust in physicians and everyday discrimination with prolonged symptom duration (greater than the median duration for any symptom).

The baseline model was adjusted for demographic covariates, including the age at diagnosis (years), region (North [Ohio, New Jersey, metropolitan Detroit, Michigan, and Illinois] or South [Tennessee, Alabama, South Carolina, North Carolina, Georgia, 
TABLE 2. Trust in Physician Response Frequencies in the AACES

\begin{tabular}{|c|c|}
\hline Trust in Physician Scenario & $\begin{array}{l}\text { No. of AACES } \\
\text { Participants (\%) }\end{array}$ \\
\hline \multicolumn{2}{|c|}{$\begin{array}{l}\text { I doubt that my doctor really cares about me as a } \\
\text { person }^{\text {a }}\end{array}$} \\
\hline Strongly disagree & $168(34.6)$ \\
\hline Disagree & $226(46.5)$ \\
\hline Neither agree nor disagree & $30(6.2)$ \\
\hline Agree & $48(9.9)$ \\
\hline Strongly agree & $14(2.9)$ \\
\hline \multicolumn{2}{|c|}{$\begin{array}{l}\text { My doctor is usually considerate of my needs and } \\
\text { puts them first }\end{array}$} \\
\hline Strongly disagree & $12(2.5)$ \\
\hline Disagree & $34(7.0)$ \\
\hline Neither agree nor disagree & $28(5.8)$ \\
\hline Agree & $261(53.7)$ \\
\hline Strongly agree & $151(31.1)$ \\
\hline \multicolumn{2}{|c|}{$\begin{array}{l}\text { I trust my doctor so much I always try to follow his/ } \\
\text { her advice }\end{array}$} \\
\hline Strongly disagree & $9(1.9)$ \\
\hline Disagree & $31(6.4)$ \\
\hline Neither agree nor disagree & $53(10.9)$ \\
\hline Agree & $272(56.0)$ \\
\hline Strongly agree & $121(24.9)$ \\
\hline \multicolumn{2}{|c|}{$\begin{array}{l}\text { If my doctor tells me something is so, then it must } \\
\text { be true }\end{array}$} \\
\hline Strongly disagree & $15(3.1)$ \\
\hline Disagree & $94(19.3)$ \\
\hline Neither agree nor disagree & $98(20.2)$ \\
\hline Agree & $227(46.7)$ \\
\hline Strongly agree & $52(10.7)$ \\
\hline \multicolumn{2}{|c|}{$\begin{array}{l}\text { I sometimes distrust my doctor's opinion and would } \\
\text { like a second one }{ }^{a}\end{array}$} \\
\hline Strongly disagree & $58(11.9)$ \\
\hline Disagree & $218(44.9)$ \\
\hline Neither agree nor disagree & $49(10.1)$ \\
\hline Agree & $137(28.2)$ \\
\hline Strongly agree & $24(4.9)$ \\
\hline \multicolumn{2}{|c|}{$\begin{array}{l}\text { I trust my doctor's judgments about my medical } \\
\text { care }\end{array}$} \\
\hline Strongly disagree & $10(2.1)$ \\
\hline Disagree & $35(7.2)$ \\
\hline Neither agree nor disagree & $33(6.8)$ \\
\hline Agree & $304(62.6)$ \\
\hline Strongly agree & $104(21.4)$ \\
\hline \multicolumn{2}{|c|}{$\begin{array}{l}\text { I feel my doctor does not do everything he/she } \\
\text { should for my medical care }\end{array}$} \\
\hline Strongly disagree & $82(16.9)$ \\
\hline Disagree & $272(56.0)$ \\
\hline Neither agree nor disagree & $38(7.8)$ \\
\hline Agree & $70(14.4)$ \\
\hline Strongly agree & $24(4.9)$ \\
\hline \multicolumn{2}{|c|}{$\begin{array}{l}\text { I trust my doctor to put my medical needs above } \\
\text { all other considerations when treating my medical } \\
\text { problems }\end{array}$} \\
\hline Strongly disagree & $10(2.1)$ \\
\hline Disagree & $35(7.2)$ \\
\hline Neither agree nor disagree & $40(8.2)$ \\
\hline Agree & $306(63.0)$ \\
\hline Strongly agree & $95(19.5)$ \\
\hline \multicolumn{2}{|c|}{$\begin{array}{l}\text { My doctor is a real expert in taking care of medical } \\
\text { problems like mine }\end{array}$} \\
\hline Strongly disagree & $16(3.3)$ \\
\hline Disagree & $54(11.1)$ \\
\hline Neither agree nor disagree & $57(11.7)$ \\
\hline Agree & $264(54.3)$ \\
\hline Strongly agree & $95(19.5)$ \\
\hline
\end{tabular}

TABLE 2. Continued

\begin{tabular}{lc}
\hline Trust in Physician Scenario & $\begin{array}{c}\text { No. of AACES } \\
\text { Participants (\%) }\end{array}$ \\
\hline I trust my doctor to tell me if a mistake was made & \\
about my treatment & $10(2.1)$ \\
Strongly disagree & $59(12.1)$ \\
Disagree & $59(12.1)$ \\
Neither agree nor disagree & $276(56.8)$ \\
Agree & $82(16.9)$ \\
Strongly agree & \\
I sometimes worry that my doctor may not keep the & \\
information we discuss totally private ${ }^{a}$ & $136(28.0)$ \\
Strongly disagree & $293(60.3)$ \\
Disagree & $36(7.4)$ \\
Neither agree nor disagree & $18(3.7)$ \\
Agree & $3(0.6)$ \\
Strongly agree & \\
\hline
\end{tabular}

Abbreviation: AACES, African American Cancer Epidemiology Study. ${ }^{a}$ Responses are coded such that a higher score indicates higher trust.

and Texas]), body mass index $(<25,25$ to $<30,30$ to $<35$, or $\geq 35 \mathrm{~kg} / \mathrm{m}^{2}$ ), marital status (single, partnered, or widowed/divorced), and modified Charlson Comorbidity Index $(0,1,2,3$, or $\geq 4) .{ }^{16}$ Model 2 was also adjusted for socioeconomic status measures, including education (high school or less, some post-high school training, or college or graduate degree) and income. Income data were collected with categorical ranges and were modeled as the midpoint of each bounded category $(\$ 10,000, \$ 17,500$, $\$ 37,500, \$ 62,500, \$ 87,500$, or $\$ 100,000)$. The final model also included measures of access to care, including health insurance (Medicare, Medicaid, private insurance, or uninsured), not having a regular physician (yes or no), self-reported barriers to seeking care (yes or no), and primary care provider density (number of clinically active primary care providers in the primary care referral area per 100,000 population). ${ }^{17}$

Two sensitivity analyses were performed with different definitions of prolonged symptom duration. Overall median symptom duration and overall mean symptom duration were used as cut points to define the outcome indicator instead of symptom-specific durations. Time to interview was also evaluated as a possible source of bias.

$P$ values $<.05$ were considered statistically significant, and all analyses were performed with SAS version 9.4 (SAS Institute).

\section{RESULTS}

The median symptom duration and symptom frequency are presented in Supporting Table 1. This resulted in 302 women who had a prolonged symptom duration and 184 women who did not. On average, women had 3 symptoms lasting longer than the median duration. 
TABLE 3. Characteristics of Women With and Without a Prolonged Symptom Duration in the African American Cancer Epidemiology Study

\begin{tabular}{|c|c|c|c|}
\hline Characteristic & Prolonged Symptom Duration $(n=302)$ & Nonprolonged Symptom Duration $(n=184)$ & $P$ \\
\hline Age, mean (SD), y & $58.1(10.5)$ & $57.3(11.1)$ & .40 \\
\hline Histology, No. (\%) & & & .55 \\
\hline Serous & $174(57.6)$ & $111(60.3)$ & \\
\hline Mucinous & $17(5.6)$ & $7(3.8)$ & \\
\hline Endometrioid & $37(12.3)$ & $20(10.9)$ & \\
\hline Clear cell & $11(3.6)$ & $3(1.6)$ & \\
\hline Other & $63(20.9)$ & $43(23.4)$ & \\
\hline Stage, No. (\%) & & & .21 \\
\hline 1 & $67(22.2)$ & $38(20.7)$ & \\
\hline II & 34 (11.3) & $15(8.2)$ & \\
\hline III & $168(55.6)$ & $99(53.8)$ & \\
\hline IV & $17(5.6)$ & $20(10.9)$ & \\
\hline Unstaged & $16(5.3)$ & $12(6.5)$ & \\
\hline Region, No. (\%) & & & .74 \\
\hline North & $65(21.5)$ & $42(22.8)$ & \\
\hline South & $237(78.5)$ & $142(77.2)$ & \\
\hline Marital status, No. (\%) & & & .003 \\
\hline Single & 58 (19.2) & $56(30.4)$ & \\
\hline Partnered & $97(32.1)$ & $64(34.8)$ & \\
\hline Widowed/divorced & $147(48.7)$ & $64(34.8)$ & \\
\hline Charlson index, No. (\%) & & & $<.001$ \\
\hline 0 & $92(30.5)$ & $86(46.7)$ & \\
\hline 1 & $74(24.5)$ & $44(23.9)$ & \\
\hline 2 & $51(16.9)$ & $25(13.6)$ & \\
\hline 3 & $31(10.3)$ & $18(9.8)$ & \\
\hline$\geq 4$ & $54(17.9)$ & $11(6.0)$ & \\
\hline Body mass index, No. (\%) & & & .15 \\
\hline$<25 \mathrm{~kg} / \mathrm{m}^{2}$ & $37(12.3)$ & $35(19.0)$ & \\
\hline 25 to $<30 \mathrm{~kg} / \mathrm{m}^{2}$ & $77(25.5)$ & $47(25.5)$ & \\
\hline 30 to $<35 \mathrm{~kg} / \mathrm{m}^{2}$ & $88(29.1)$ & $54(29.3)$ & \\
\hline$\geq 35 \mathrm{~kg} / \mathrm{m}^{2}$ & $100(33.1)$ & $48(26.1)$ & \\
\hline $\begin{array}{l}\text { Annual household income }(\$ 10,000) \text {, mean } \\
\text { (SD) }\end{array}$ & $4.00(3.0)$ & $3.87(2.8)$ & $.92^{\mathrm{a}}$ \\
\hline Education, No. (\%) & & & .70 \\
\hline High school or less & $126(41.7)$ & $84(45.7)$ & \\
\hline Some post-high school training & $79(26.2)$ & $45(24.5)$ & \\
\hline College or graduate degree & $97(32.1)$ & 55 (29.9) & \\
\hline Have regular physician, No. (\%) & & & .67 \\
\hline Yes & $265(87.7)$ & $159(86.4)$ & \\
\hline No & $37(12.3)$ & $25(13.6)$ & \\
\hline Self-reported barrier to seeking care, No. (\%) & & & .02 \\
\hline Yes & $70(23.2)$ & $27(14.7)$ & \\
\hline No & $232(76.8)$ & $157(85.3)$ & \\
\hline $\begin{array}{l}\text { Primary care provider density (per 100,000 } \\
\text { population), mean (SD) }\end{array}$ & $70.9(19.8)$ & $69.8(17.0)$ & .52 \\
\hline Insurance, No. (\%) & & & .86 \\
\hline Private & $116(38.4)$ & $75(40.8)$ & \\
\hline Medicare & $90(29.8)$ & $49(26.6)$ & \\
\hline Medicaid & $64(21.2)$ & $42(22.8)$ & \\
\hline Uninsured & $32(10.6)$ & $18(9.8)$ & \\
\hline Total trust in physician score, mean (SD) & $41.3(8.4)$ & $42.7(7.0)$ & .06 \\
\hline $\begin{array}{l}\text { Mean everyday discrimination score, mean } \\
\text { (SD) }\end{array}$ & $0.53(0.72)$ & $0.31(0.52)$ & $<.001^{\mathrm{a}}$ \\
\hline
\end{tabular}

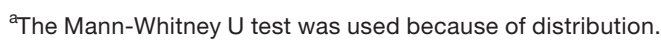

Descriptive characteristics are presented in Table 3. On average, women were diagnosed in their late 50 s and were obese (body mass index $>30 \mathrm{~kg} / \mathrm{m}^{2}$ ). Most women reported having a regular family physician and were insured by private health insurance or Medicare. The average supply of clinically active primary care providers in their primary care service area was approximately 70 providers per 100,000 population, and $80 \%$ of the women reported no barriers to seeking care (Table 3 ).

We observed measurable differences in the Charlson index, marital status, self-reported barriers to care seeking, attitudes toward physicians, and perceived discrimination between women who did and did not experience prolonged symptom duration. The proportion of women 
with a Charlson index of 4 or more was 3 times greater among women with symptom delays in comparison with those without delays (Table 3).

Women with prolonged symptom duration had lower trust in physician scores, and both groups had response averages below "agree" (response sum, 44) across the 11 questions. Women with prolonged symptom duration also had more frequent experiences of everyday discrimination. Both groups had average discrimination scores between 0 and 1 , which reflected an average discrimination frequency between never and less than once a year $(P<.001)$.

The distributions of responses to the everyday discrimination scenarios in the interview are displayed in Table 1 . Notably, 32\% of the women reported being treated with less courtesy or respect than other people, $33 \%$ perceived receiving poorer service than other people at restaurants or stores, and $32 \%$ felt that people acted as if they were not smart. Cronbach's $\alpha$ for the Everyday Discrimination Scale was 0.73 in this analytic sample.

Table 2 presents the trust in physician statements and responses. Generally, responses more frequently indicated trust; however, several scenarios had substantial numbers of responses indicating low trust (Table 2). Cronbach's $\alpha$ for the Trust in Physician Scale was 0.92 in this analytic sample.

Table 4 presents the ORs and 95\% CIs from the multivariable logistic regression models for prolonged symptom duration. Model 1 was adjusted for demographic characteristics. A 1-unit increase in the everyday discrimination score (eg, from never to almost monthly) was associated with $77 \%$ higher odds of prolonged symptom duration (OR, 1.77; 95\% CI, 1.25-2.52). Trust in physicians was not associated with an increased risk of symptom duration (OR, 0.86; 95\% CI, 0.67-1.11). Further adjustments for measures of socioeconomic status, including education and income, resulted in little change in the strength of the associations for discrimination and trust (model 2 in Table 4). Furthermore, accounting for access-to-care covariates resulted in a negligible change in the magnitude of the association for discrimination (OR, 1.74; 95\% CI, 1.22-2.49) and physician trust (OR, 0.86; 95\% CI, 0.66-1.11; model 3 in Table 4).

Noteworthy associations for other variables included in the fully adjusted model were observed. Women with a Charlson index score $\geq 4$ had 4.6 times the odds of prolonged symptom duration in comparison with women with no comorbid conditions (OR, 4.62; 95\% CI, 2.12-10.1). Compared with single women, divorced or widowed women had twice the odds of prolonged symptom duration (OR, 2.09; 95\% CI, 1.24-3.54). Having a self-reported barrier to going to the doctor increased the odds of prolonged symptom duration 96\% (OR, 1.96; 95\% CI, 1.10-3.50).

In sensitivity analyses, no meaningful changes to the results were observed with the different definitions of outcome except for 1 covariate, self-reported barriers to care, for which the previously observed association was no longer present (data not shown). There was no association between prolonged symptom duration and time to interview in models, nor did including time to interview as a covariate in models change the results.

\section{DISCUSSION}

In summary, in this sample of 486 black women with ovarian cancer, everyday discrimination was associated with prolonged symptom duration. Particularly noteworthy was our finding that despite reflecting broader everyday life context, more frequent everyday discrimination increased the odds of prolonged symptom duration $74 \%$ in fully adjusted models, but health system-specific trust in physicians was not associated with prolonged symptom duration. This finding is important because material components for accessing care have not been sufficient in explaining racial disparities in ovarian cancer care, and this is the first study to evaluate possible interpersonal contributions.

Although perceived discrimination has not previously been evaluated in women with ovarian cancer, our results are consistent with findings in other populations. ${ }^{18,19}$ Although our findings reflect a specific prediagnostic window, perceived discrimination has similarly been associated with delays in a breast cancer diagnosis after an abnormal mammogram. 'These results align with the study of Casagrande et $\mathrm{al}^{10}{ }^{10}$ who found that discrimination experiences were associated with prolonged symptom duration and nonadherence to medical recommendations.

In contrast, other studies have not found an association between perceived discrimination and low health care engagement or have found the opposite relationship. ${ }^{18,20}$ These mixed findings are likely due to differences in the burden of comorbid conditions, the racial identity of study participants, and the measures of health care utilization. Many studies evaluate routine or preventive services with a clear guideline for care seeking. However, seeking care for ovarian cancer symptoms relies more heavily on patient perception and, often, persistence. ${ }^{11,12}$ Although the individual symptoms are 
TABLE 4. Adjusted ORs for Associations of Trust in Physicians and Everyday Discrimination With Prolonged Symptom Duration in the African American Cancer Epidemiology Study

\begin{tabular}{|c|c|c|c|}
\hline & \multicolumn{3}{|c|}{ OR $(95 \% \mathrm{Cl})$} \\
\hline & Model $1^{a}$ & Model $2^{b}$ & Model $3^{c}$ \\
\hline Trust in physician score (10 units) & $0.86(0.67-1.11)$ & $0.84(0.65-1.09)$ & $0.86(0.66-1.11)$ \\
\hline Mean discrimination score & $1.77^{\mathrm{d}}(1.25-2.52)$ & $1.75^{\mathrm{d}}(1.23-2.48)$ & $1.74^{\mathrm{d}}(1.22-2.49)$ \\
\hline Age (y) & $1.00(0.98-1.02)$ & $1(0.98-1.02)$ & $1(0.98-1.02)$ \\
\hline \multicolumn{4}{|l|}{ Region } \\
\hline South & 1.0 (reference) & 1.00 (reference) & 1.00 (reference) \\
\hline North & $0.82(0.51-1.32)$ & $0.78(0.48-1.26)$ & $0.7(0.41-1.21)$ \\
\hline \multicolumn{4}{|l|}{ Marital status } \\
\hline Single & 1.00 (reference) & 1.00 (reference) & 1.00 (reference) \\
\hline Partnered & $1.41(0.84-2.38)$ & $1.29(0.75-2.22)$ & $1.34(0.77-2.34)$ \\
\hline Divorced/widowed & $2.06^{d}(1.23-3.46)$ & $2.03^{d}(1.21-3.42)$ & $2.09^{d}(1.24-3.54)$ \\
\hline \multicolumn{4}{|l|}{ Body mass index } \\
\hline$<25 \mathrm{~kg} / \mathrm{m}^{2}$ & 1.00 (reference) & 1.00 (reference) & 1.00 (reference) \\
\hline 25 to $<30 \mathrm{~kg} / \mathrm{m}^{2}$ & $1.48(0.80-2.73)$ & $1.51(0.81-2.82)$ & $1.55(0.83-2.93)$ \\
\hline 30 to $<35 \mathrm{~kg} / \mathrm{m}^{2}$ & $1.33(0.73-2.44)$ & $1.34(0.73-2.46)$ & $1.31(0.70-2.44)$ \\
\hline$\geq 35 \mathrm{~kg} / \mathrm{m}^{2}$ & $1.52(0.82-2.80)$ & $1.56(0.84-2.89)$ & $1.55(0.83-2.90)$ \\
\hline \multicolumn{4}{|l|}{ Charlson index } \\
\hline 0 & 1.00 (reference) & 1.00 (reference) & 1.00 (reference) \\
\hline 1 & $1.43(0.87-2.36)$ & $1.46(0.89-2.40)$ & $1.48(0.89-2.46)$ \\
\hline 2 & $1.73(0.96-3.11)$ & $1.8(0.99-3.27)$ & $1.73(0.94-3.18)$ \\
\hline 3 & $1.31(0.66-2.60)$ & $1.39(0.69-2.78)$ & $1.32(0.65-2.72)$ \\
\hline$\geq 4$ & $4.13^{d}(1.96-8.72)$ & $4.45^{d}(2.09-9.47)$ & $4.62^{d}(2.12-10.1)$ \\
\hline \multicolumn{4}{|l|}{ Education } \\
\hline College or graduate degree & - & 1.00 (reference) & 1.00 (reference) \\
\hline Some post-high school training & - & $1.03(0.60-1.76)$ & $1.07(0.62-1.85)$ \\
\hline High school or less & - & $0.82(0.49-1.40)$ & $0.85(0.49-1.45)$ \\
\hline Income $(\$ 10,000)$ & - & $1.04(0.95-1.13)$ & $1.06(0.97-1.16)$ \\
\hline \multicolumn{4}{|l|}{ Insurance } \\
\hline Private & - & - & 1.00 (reference) \\
\hline Medicare & - & - & $1.08(0.59-1.96)$ \\
\hline Medicaid & - & - & $0.99(0.53-1.86)$ \\
\hline Uninsured & - & - & $1.15(0.53-2.48)$ \\
\hline No regular physician & - & - & $0.91(0.48-1.73)$ \\
\hline Barrier to care seeking & - & - & $1.96^{\mathrm{e}}(1.10-3.50)$ \\
\hline $\begin{array}{l}\text { Primary care provider density ( } 10 \text { physicians } \\
\text { per } 100,000 \text { population) }\end{array}$ & - & - & $1.06(0.94-1.19)$ \\
\hline
\end{tabular}

Abbreviations: $\mathrm{Cl}$, confidence interval; OR, odds ratio.

${ }^{a}$ Model 1: trust in physician score, mean everyday discrimination score, age, region, marital status, body mass index, and Charlson Comorbidity Index.

${ }^{\mathrm{b}}$ Model 2: trust in physician score, mean everyday discrimination score, age, region, marital status, body mass index, Charlson Comorbidity Index, education, and income.

${ }^{c}$ Model 3: trust in physician score, mean everyday discrimination score, age, region, marital status, body mass index, Charlson Comorbidity Index, education, income, insurance, no regular physician, barrier to care seeking, and primary care provider density.

${ }^{\mathrm{d}} P<.01$.

${ }^{\mathrm{e}} P<.05$.

nonspecific, combinations of symptoms, onset, and intensity of symptoms can be important indicators of disease. $^{21}$

The Everyday Discrimination Scale showed reasonable internal consistency in this analysis, particularly because the scale has only 5 items. Although everyday discrimination was modeled as a mean score, to better understand these findings, each discrimination scenario was modeled separately (results not shown), and "people act as if I am not smart" was the only scenario associated with prolonged symptom duration. This suggests that one mechanism of this relationship may be stereotype threat, which is defined as "a disruptive psychological state that people experience when they feel at risk for confirming a negative stereotype associated with their social identity." ${ }^{22}$ Stereotype threat is associated with increased stress, cognitive burden, avoidance of situations that induce the threat, and lower health care utilization. ${ }^{22,23}$ It may also underlie increased distrust of physicians and lower health care satisfaction. ${ }^{22,23}$

Trust in physicians was not associated with prolonged symptom duration. It is well established that black patients are more likely to mistrust the health care system than white patients. ${ }^{24}$ Because this analysis was limited to black women, trust may contribute less variation. Other studies suggest that trust in physicians is 
predicted by perceived discrimination. ${ }^{25}$ In our analysis, bivariate tests did not support discrimination as a mediator of physician trust (data not shown), and trust was not highly correlated with the everyday discrimination score $(r=-0.11)$.

Finally, 2 confounders had significant associations with prolonged symptom duration. A Charlson index score $\geq 4$ had the largest association with prolonged symptom duration in this analysis. These findings are expected because many ovarian cancer symptoms overlap with a wide range of health issues. This association likely reflects a masking effect by which poorer health makes it more difficult to identify symptoms attributable to ovarian cancer. Similarly, women who lost a spouse by either death or divorce were twice as likely as single women to have prolonged symptom duration. This may reflect a decline in mental health or a change in social support. ${ }^{26}$

This study has several strengths. The AACES provides an unprecedented sample size of black women with ovarian cancer. This study was uniquely positioned to analyze previously unaddressed exposures among women with ovarian cancer. Although several studies have documented disparities in ovarian cancer survival and treatment, most data have come from medical claims with which studying interpersonal exposures was not possible. Also, our primary exposure measures were validated multi-item scales, which have been found to be more reliable than single-item measures. ${ }^{27}$ These measures also showed good internal consistency in this analytic data set. Finally, we used a symptom-specific approach that reflects the complexity of changes in the body and their different associated meanings. ${ }^{28}$

\section{Limitations}

Study participants were slightly younger and healthier than nonparticipants, and this may limit the generalizability of these findings, although this is a common challenge in ovarian cancer studies. ${ }^{13}$

Prolonged symptom duration reflects several components (Fig. 1). However, it would be nigh impossible to disaggregate this outcome without a prospective design. Although our outcome cannot parse the individual contributions of this time period apart, it reflects a longer time period before diagnosis that could be acted upon. Despite steps in health system control such as timely appointment availability or misattribution of symptoms to other diseases, patient self-efficacy and persistence in pursuing resolution of symptoms are key drivers to navigating those barriers. ${ }^{11,12}$
The outcome measure also relied on retrospectively reported symptoms. Although measurement error is possible, all participants were recalling symptoms from the recent past, so this was unlikely to introduce bias. Including the time to interview did not affect results, and the duration of symptoms in our study is in line with previous findings. ${ }^{21}$

These data were collected cross-sectionally and could be subject to reverse causation. A woman who experienced a prolonged symptom duration despite prompt care seeking may possibly perceive more discrimination because of her health care experience. Our hope is that the discrimination measure, which assessed specific everyday experiences rather than health care experiences, minimizes this possible bias.

Finally, discrimination and trust are sensitive topics to ask about in a research survey. These sections were placed toward the end of the survey to allow the interviewer and the respondent to develop rapport before they were approached. Despite this, nonresponse to the trust in physician section of the questionnaire was the largest source of exclusion after questionnaire length (Fig. 2). These women had higher everyday discrimination scores, but they were not more likely to have prolonged symptom duration, and this suggests that any selection bias is likely to be minimal.

In conclusion, this work is a novel first step in understanding the relationship between interpersonal exposures and racial disparities in ovarian cancer care. More equitable access to ovarian cancer care necessitates that women feel comfortable about advocating for their needs and trust their self-assessment of their symptoms. These results point to the social context in daily life playing a role in receiving optimal ovarian cancer care and suggest that more research is needed on the effects of interpersonal barriers in the ovarian cancer care continuum. Future work should include other racial and ethnic groups and consider the role of health providers.

\section{FUNDING SUPPORT}

The African American Cancer Epidemiology Study was funded by the National Cancer Institute (R01CA142081). Additional support was provided by the Metropolitan Detroit Cancer Surveillance System with federal funds from the National Cancer Institute (National Institutes of Health, Department of Health and Human Services) under contract HHSN261201000028C and by the Epidemiology Research Core, which is supported in part by a National Cancer Institute Center Grant (P30CA22453) to the Karmanos Cancer Institute (Wayne State University School of Medicine) and by a National Cancer Institute Center Grant (P30CA072720) to the Rutgers Cancer Institute of New Jersey. The funders had no role in the design, analysis, or writing of this article. The data set forth in Tables 3 and 4 (physician supply) of this 
article were obtained from the Dartmouth Atlas, which is funded by the Robert Wood Johnson Foundation and the Dartmouth Clinical and Translational Science Institute under award number UL1TR001086 from the National Center for Advancing Translational Sciences of the National Institutes of Health.

\section{CONFLICT OF INTEREST DISCLOSURES}

The authors made no disclosures.

\section{AUTHOR CONTRIBUTIONS}

Megan A. Mullins: Study concept, data analysis, drafting of the initial manuscript, substantive feedback on manuscript drafts, approval of the final version of this work, and agreement to be accountable. Lauren C. Peres: Responsibility for enrolling study participants, data collection, substantive feedback on manuscript drafts, approval of the final version of this work, and agreement to be accountable. Anthony J. Alberg: Responsibility for enrolling study participants, data collection, substantive feedback on manuscript drafts, approval of the final version of this work, and agreement to be accountable. Elisa V. Bandera: Responsibility for enrolling study participants, data collection, substantive feedback on manuscript drafts, approval of the final version of this work, and agreement to be accountable. Jill S. Barnholtz-Sloan: Responsibility for enrolling study participants, data collection, substantive feedback on manuscript drafts, approval of the final version of this work, and agreement to be accountable. Melissa L. Bondy: Responsibility for enrolling study participants, data collection, substantive feedback on manuscript drafts, approval of the final version of this work, and agreement to be accountable. Ellen Funkhouser: Responsibility for enrolling study participants, data collection, substantive feedback on manuscript drafts, approval of the final version of this work, and agreement to be accountable. Patricia G. Moorman: Responsibility for enrolling study participants, data collection, substantive feedback on manuscript drafts, approval of the final version of this work, and agreement to be accountable. Edward S. Peters: Responsibility for enrolling study participants, data collection, substantive feedback on manuscript drafts, approval of the final version of this work, and agreement to be accountable. Paul D. Terry: Responsibility for enrolling study participants, data collection, substantive feedback on manuscript drafts, approval of the final version of this work, and agreement to be accountable. Ann G. Schwartz: Responsibility for enrolling study participants, data collection, substantive feedback on manuscript drafts, approval of the final version of this work, and agreement to be accountable. Andrew B. Lawson: Substantive feedback on manuscript drafts, approval of the final version of this work, and agreement to be accountable. Joellen M. Schildkraut: Responsibility for enrolling study participants, data collection, substantive feedback on manuscript drafts, approval of the final version of this work, and agreement to be accountable. Michele L. Cote: Responsibility for enrolling study participants, data collection, substantive feedback on manuscript drafts, approval of the final version of this work, and agreement to be accountable.

\section{REFERENCES}

1. Surveillance, Epidemiology, and End Results Program. Cancer Stat Facts: Ovarian Cancer. Accessed May 9, 2018. https://seer.cancer. gov/statfacts/html/ovary.html

2. Park HK, Ruterbusch JJ, Cote ML. Recent trends in ovarian cancer incidence and relative survival in the United States by race/ ethnicity and histologic subtypes. Cancer Epidemiol Biomarkers Prev. 2017;26:1511-1518. doi:10.1158/1055-9965.EPI-17-0290

3. Jemal A, Ward EM, Johnson CJ, et al. Annual Report to the Nation on the Status of Cancer, 1975-2014, Featuring Survival. J Natl Cancer Inst. 2017;109. doi:10.1093/jnci/djx030.

4. Srivastava SK, Ahmad A, Miree O, et al. Racial health disparities in ovarian cancer: not just black and white. J Ovarian Res. 2017;10:58. doi:10.1186/s13048-017-0355-y

5. Terplan M, Smith EJ, Temkin SM. Race in ovarian cancer treatment and survival: a systematic review with meta-analysis. Cancer Causes Control. 2009;20:1139-1150. doi:10.1007/s10552-009-9322-2
6. Bristow RE, Chang J, Ziogas A, Campos B, Chavez LR, AntonCulver H. Sociodemographic disparities in advanced ovarian cancer survival and adherence to treatment guidelines. Obstet Gynecol. 2015;125:833-842. doi:10.1097/AOG.0000000000000643

7. Bandera EV, Lee VS, Rodriguez-Rodriguez L, Powell CB, Kushi LH. Racial/ethnic disparities in ovarian cancer treatment and survival. Clin Cancer Res. 2016;22:5909-5914. doi:10.1158/1078-0432. CCR-16-1119

8. Jacobs EA, Rathouz PJ, Karavolos K, et al. Perceived discrimination is associated with reduced breast and cervical cancer screening: the Study of Women's Health Across the Nation (SWAN). J Womens Health (Larchmt). 2014;23:138-145. doi:10.1089/jwh.2013.4328

9. Perez-Stable EJ, Afable-Munsuz A, Kaplan CP, et al. Factors influencing time to diagnosis after abnormal mammography in diverse women. J Womens Health (Larchmt). 2013;22:159-166. doi:10.1089/ jwh.2012.3646

10. Casagrande SS, Gary TL, LaVeist TA, Gaskin DJ, Cooper LA. Perceived discrimination and adherence to medical care in a racially integrated community. J Gen Intern Med. 2007;22:389-395. doi:10.1007/s11606-006-0057-4

11. Evans J, Ziebland S, McPherson A. Minimizing delays in ovarian cancer diagnosis: an expansion of Andersen's model of 'total patient delay'. Fam Pract. 2007;24:48-55. doi:10.1093/fampra/cml063

12. Seibaek L, Petersen LK, Blaakaer J, Hounsgaard L. Symptom interpretation and health care seeking in ovarian cancer. BMC Womens Health. 2011;11:31. doi:10.1186/1472-6874-11-31

13. Schildkraut JM, Alberg AJ, Bandera EV, et al. A multi-center population-based case-control study of ovarian cancer in AfricanAmerican women: the African American Cancer Epidemiology Study (AACES). BMC Cancer. 2014;14:688. doi:10.1186/14712407-14-688

14. Sternthal Slopen N, Williams DR. Racial disparities in health: how much does stress really matter? Du Bois Rev. 2011;8:95-113.

15. Anderson LA, Dedrick RF. Development of the Trust in Physician Scale: a measure to assess interpersonal trust in patient-physician relationships. Psychol Rep. 1990;67(3 pt 2):1091-1100. doi:10.2466/ pr0.1990.67.3f.1091

16. Charlson ME, Pompei P, Ales KL, MacKenzie CR. A new method of classifying prognostic comorbidity in longitudinal studies: development and validation. I Chronic Dis. 1987;40:373-383. doi:10.1016/0021-9681(87)90171-8

17. Dartmouth Atlas of Health Care. PCSA Data Download-2010 (Census Tract Basis). Downloads. Accessed May 1, 2018. http://archi ve.dartmouthatlas.org/tools/downloads.aspx?tab=42

18. Mouton CP, Carter-Nolan PL, Makambi KH, et al. Impact of perceived racial discrimination on health screening in black women.J Health Care Poor Underserved. 2010;21:287-300. doi:10.1353/hpu.0.0273

19. Wamala S, Merlo J, Bostrom G, Hogstedt C. Perceived discrimination, socioeconomic disadvantage and refraining from seeking medical treatment in Sweden. J Epidemiol Community Health. 2007;61:409-415. doi:10.1136/jech.2006.049999

20. Fazeli Dehkordy S, Hall KS, Dalton VK, Carlos RC. The link between everyday discrimination, healthcare utilization, and health status among a national sample of women. J Womens Health (Larchmt). 2016;25:1044-1051. doi:10.1089/jwh.2015.5522

21. Vine MF, Calingaert B, Berchuck A, Schildkraut JM. Characterization of prediagnostic symptoms among primary epithelial ovarian cancer cases and controls. Gynecol Oncol. 2003;90:75-82.

22. Aronson J, Burgess D, Phelan SM, Juarez L. Unhealthy interactions: the role of stereotype threat in health disparities. Am J Public Health. 2012;103:50-56. doi:10.2105/AJPH.2012.300828

23. Abdou CM, Fingerhut AW, Jackson JS, Wheaton F. Healthcare stereotype threat in older adults in the Health and Retirement Study. Am J Prev Med. 2016;50:191-198. doi:10.1016/j.amepre.2015.07.034

24. Guerrero N, Mendes de Leon CF, Evans DA, Jacobs EA. Determinants of trust in health care in an older population. J Am Geriatr Soc. 2015;63:553-557. doi:10.1111/jgs.13316

25. Hong HC, Ferrans CE, Park C, Lee H, Quinn L, Collins EG. Effects of perceived discrimination and trust on breast cancer screening among Korean American women. Womens Health Issues. 2018;28:188196. doi:10.1016/j.whi.2017.11.001 
26. Musick K, Bumpass L. Re-examining the case for marriage: union formation and changes in well-being. J Marriage Fam. 2012;74:1-18. doi:10.1111/j.1741-3737.2011.00873.x

27. Krieger N, Smith K, Naishadham D, Hartman C, Barbeau EM. Experiences of discrimination: validity and reliability of a self-report measure for population health research on racism and health. Soc Sci Med. 2005;61:1576-1596. doi:10.1016/j.socscimed.2005.03.006

28. Dobson CM, Russell AJ, Rubin GP. Patient delay in cancer diagnosis: what do we really mean and can we be more specific? BMC Health Serv Res. 2014;14:387. doi:10.1186/1472-6963-14-387 